\title{
Breathlessness in elderly individuals is related to low lung function and reversibility of airway obstruction
}

\author{
H.M. Boezen*, B. Rijcken*, J.P. Schouten*, D.S. Postma**
}

Breathlessness in elderly individuals is related to low lung function and reversibility of airway obstruction. H.M. Boezen, B. Rijcken, J.P. Schouten, D.S. Postma. CERS Journals Ltd 1998.

ABSTRACT: The perception of breathlessness is a subject-related factor which is linked to respiratory disease, cardiac disease and overweight. We studied the distribution of breathlessness, its association with respiratory disease, cardiac disease and overweight, as well as its association with lung function, reversibility of airway obstruction ("reversibility") and peak expiratory flow (PEF) variability in an elderly population.

Data on breathlessness (rated with Borg scale), lung function, reversibility, PEF variability, respiratory symptoms, cardiac disease and overweight were collected in a random sample of 210 elderly ( $>55$ yrs old) who participated in a physical fitness test. Individuals with a Borg score $>0$ were taken to have breathlessness.

Subjects with a Borg score $>0(n=50,24 \%)$ were three to five times more likely to have a low lung function and large reversibility than subjects with a Borg score of zero, independent of the presence of respiratory symptoms, cardiac disease or overweight, although these three factors were all associated with low lung function and a large reversibility and PEF variability. Reversibility was not associated with PEF variability whatsoever.

In elderly individuals, breathlessness is frequently present. Assessment of breathlessness using the Borg-scale seems an important clinical measurement, because it is an important independent predictor of lung function impairment in the elderly.

Eur Respir J 1998; 12: 805-810.
Depts of *Epidemiology and Statistics, University of Groningen and **Pulmonology, University Hospital Groningen, The Netherlands.

Correspondence: D.S. Postma

Dept of Pulmonology

University Hospital Groningen

Hanzeplein 1

NL-9713 GZ Groningen

The Netherlands

Fax: 31503619320

Keywords: Breathlessness

elderly

lung function

peak expiratory flow variability

reversibility

Received: December 101997

Accepted after revision April 181998

Supported by a grant from Stichting Astma Bestrijding, Winterswijk, The Netherlands. The Health insurer was "Het Groene Land", Zwolle, The Netherlands.
During ageing there is a slow progression of occasional, transient, respiratory symptoms towards a more chronic symptomatic status. Such individuals are likely to adapt gradually to their symptoms. This adaptation process has been described in patients with respiratory disease. Reduced sensory awareness of induced airway obstruction has been observed in asthmatic patients with low levels of lung function [1] as well as in subjects with long-standing respiratory disease [2]. Thus, loss of sensory awareness may constitute an explanation for the gradual adaptation to chronic airway obstruction in patients with respiratory disease.

There is a difference between patients with chronic obstructive pulmonary disease (COPD) and patients with asthma with respect to perception of bronchoconstriction and bronchodilatation [3]. Thus, perception of dyspnoea is dependent on the nature of a subject's chronic respiratory symptoms. Furthermore, in subjects without chronic respiratory symptoms one can induce airway obstruction, which is not perceived or recognized as dyspnoea [4]. Perception, thus, seems to be a subject-related factor of importance in studying airway obstruction. It is possible that perception is a factor associated with airway obstruction, independently of the presence of chronic respiratory symptoms.

Breathlessness is not only related to respiratory disease, since it is also associated with cardiac diseases [5], as well as with a combination of both [6]. Therefore, when studying breathlessness in association with respiratory disease, the presence of cardiac disease may be an important factor, which potentially modifies the relationship between the level of lung function and respiratory symptoms and breathlessness. The latter could be especially important in older subjects, since the prevalence of cardiac disease increases with age. Another modifying factor in the association between respiratory symptoms, level of lung function and breathlessness might be overweight.

Data were collected on the presence of breathlessness and chronic respiratory symptoms, cardiac disease, weight, lung function, bronchodilator response and variability in peak expiratory flow (PEF) in an elderly population. The aim of the study was to describe the prevalence of breathlessness and to investigate whether breathlessness is a predictor of lung function, bronchodilator response and PEF variability in a sample of elderly subjects.

\section{Methods}

\section{Population sample}

The study was performed in the county of Drenthe, The Netherlands. In five municipalities a random sample of 1,505 subjects was drawn (660 males and 845 females) 
from the population register (excluding the addresses of nursing homes and rest homes for the elderly) and stratified by age-groups $(55-59,60-64,65-69,70-74$ and $\breve{S} 75$ yrs). Subjects in this sample were invited to participate in a physical fitness test for the elderly and $462(31 \%)$ responded to this invitation. Those subjects who responded to the invitation were a good representation of the total population with regard to age and sex distribution, with the exception of subjects over the age of $75 \mathrm{yrs}$, who were relatively under-represented at the fitness test.

A random sample of 277 of the 462 subjects who performed the physical fitness test was included in a survey on respiratory health. There were no significant differences in age or sex distributions between the population that was randomly selected to participate in the survey on respiratory health and those subjects who were not. Thus, the participants of the respiratory survey were considered to be a good representation of all subjects who performed the fitness test. Participants received written and verbal information before the respiratory survey and signed an informed consent form. The respiratory survey was approved by the Medical Ethics Committee of the University Hospital Groningen, The Netherlands.

\section{Borg score $>0$}

The modified Borg scale [1,7] was used to rate the degree of breathlessness at rest as perceived by the subject. Subjects had rested for at least $10 \mathrm{~min}$ before measurement of the Borg score. Breathlessness was described to the subjects as "shortness of breath or breathlessness". Subjects were asked to rate their breathlessness by indicating a score between 0 (no breathlessness at all) and 10 (maximal breathlessness). The Borg score was determined before the bronchodilator test. Subjects with a Borg score of zero were considered to be free of breathlessness. Subjects with any other Borg score were taken to have breathlessness [4].

\section{Questionnaire}

Data on respiratory symptoms and smoking habits were collected by means of the standardized questionnaire of the European Community Respiratory Health Survey (ECRHS) [8]. Subjects were considered to have respiratory symptoms if they had experienced wheeze (wheezing or whistling without having a cold, at any time in the last 12 months), cough or phlegm (usually first thing in the morning, during the day or at night, in the winter). The cumulative number of cigarettes ever smoked was calculated and expressed in pack-years ( 1 pack-year=25 cigarettes $\cdot$ day $^{-1}$ during $1 \mathrm{yr}$ ).

The presence of cardiac disease was defined as a positive response to any of the following questions: "Has a doctor ever told you there were problems with your heart?"; "Do you have pain regularly around your heart or on your chest?", or "Do you use medication for your heart?". Height and weight were measured and the Quetelet Index (QI=weight/height ${ }^{2}$ ) was calculated. On the basis of their QI subjects were categorized into the groups: normal weight $(\mathrm{QI}<25)$ or overweight (QI Š25) [9].

\section{Lung function}

Manoeuvres measuring the forced expiratory volume in one second (FEV1) were performed in a sitting position, using noseclips and a rubber mouthpiece with teeth grips. Measurements were performed with a water-sealed spirometer (Lode Spirograph, D53; Lode Instruments, Groningen, The Netherlands). FEV1 was measured following an inspiratory vital capacity (IVC) measurement. FEV1 was recorded from two to five technically satisfactory manoeuvres (difference between $2 \mathrm{FEV}_{1} \partial 100 \mathrm{~mL}$ ), with the highest FEV1 value being used in the analyses. FEV1 is expressed as the percentage of the subject's predicted FEV1 (FEV1\% pred) [10].

\section{Bronchodilator response}

The bronchodilator test was performed as described in the protocol of the ECRHS [8]. FEV1 was measured before and $10 \mathrm{~min}$ after administration of $400 \mu \mathrm{g}$ salbutamol by a metered-dose inhaler via a Volumatic (Glaxo Pharmaceuticals, Zeist, the Netherlands). Subjects who had had a heart attack in the last 3 months, had any heart disease or epilepsy for which they were taking medication, or were taking $\beta$-blockers for any reason (including eye drops), were excluded from the bronchodilator test. Sixtyseven of the 277 subjects (24\%) met the exclusion criteria for the bronchodilator test. Those subjects excluded from bronchodilator testing were significantly older, had a lower FEV $1 \%$ pred and significantly more often a Borg score $>0$ and phlegm than those undergoing a bronchodilator test. Bronchodilator response was expressed continuously as the change in FEV1 as a percentage of the predicted FEV1 ( $\triangle F E V_{1} \%$ pred). Subjects with a bronchodilator $\triangle \mathrm{FEV}_{1} \%$ pred $>9 \%$ were considered to have "reversibility" [11] of airway obstruction.

\section{Variability in peak expiratory flow}

Subjects were given a mini-Wright peak flow meter (Clement Clarke International, London, UK) and were instructed by a trained technician as to the correct use of the meter and recording form [12]. Functioning of each peak flow meter was checked before distribution and upon return. Subjects had to perform PEF measurements at home for six successive days, starting on the day following the fitness test. They were instructed to record the highest values of three PEF measurements performed at home every morning on rising, and again every afternoon between 17:00 and 18:00 h, before dinner.

The highest value of the morning and the afternoon recordings was used in the analyses. If subjects were taking bronchodilator therapy, PEF values had to be measured before its use. PEF variability was expressed as the diurnal PEF variation: ((highest PEF - lowest PEF)/mean value of the two $\times 100 \%$, and as the between-day PEF variation: $S D$ $\%$ mean morning PEF, both over a minimum of 4 days. A diurnal PEF variation $>10 \%$ was defined as "high diurnal PEF variation" [13]. 


\section{Data analyses}

Complete data on breathlessness, lung function, reversibility, PEF variability, respiratory symptoms, cardiac disease, height and weight were collected in 210 subjects (88 males; 42\%). Distributions of FEV1, $\triangle \mathrm{FEV} 1 \%$ pred and PEF variability were inspected visually by normal probability plots. The Kolmogorov-Smirnov test was used to test distributions formally for normality. In the case of normal distributions, parametric tests were used.

For the diurnal PEF variation and the between-day PEF variation (both skewed distributions) log transformations were performed to achieve normalization. Analyses were performed on these log-transformed data. Means and standard deviations were transformed back to normal units (geometric means, \%sD) [14]. The Chi-squared test was used to test differences in proportions.

Associations of breathlessness, respiratory symptoms, cardiac disease and overweight with $\mathrm{FEV}_{1} \%$ pred, bronchodilator $\triangle \mathrm{FEV} 1 \%$ pred and diurnal and between-day PEF variation were assessed using linear regression models. Linear regression was performed for all independent variables separately, with simultaneous adjustment for age, sex and pack-years. The independent associations of breathlessness and respiratory symptoms, cardiac disease and overweight with low lung function level (FEV1 \% pred $<80 \%$ ), reversibility (bronchodilator $\triangle \mathrm{FEV} 1 \%$ pred $>9 \%)$ and high diurnal PEF variation $(>10 \%)$ were estimated using logistic regression, with simultaneous adjustment for each other, age, sex and pack-years. In addition, the independence of breathlessness, respiratory symptoms, cardiac disease and overweight was tested by entering interaction terms of these variables into the model. Odds ratios (OR) were considered to be significant if the $95 \%$ confidence interval $(\mathrm{CI})$ did not include the value 1 . All tests were two-sided. A value of $\mathrm{p}<0.05$ was considered to be significant. Analyses were performed with the SPSS/ PC+ V5.0 package (SPSS Inc., Chicago, IL, USA).

\section{Results}

\section{Population characteristics and lung function variables}

Complete data were collected in 210 subjects 88 males and 122 females (table 1). Of these 210 subjects 50 (24\%) had a Borg score $>0$. Among subjects with a Borg score $>0$ the percentage with an FEV $1 \%$ pred $<80 \%$ (low lung function) and a $\triangle \mathrm{FEV}_{1} \%$ pred $>9 \%$ (reversibility) was significantly higher than in subjects with a Borg score of zero. The percentage of subjects with a diurnal PEF variation $>10 \%$ (high diurnal variation) was not significantly different between subjects with a Borg score $>0$ and those with a Borg score of zero. The estimated differences in $\mathrm{FEV}_{1} \%$ pred, $\triangle \mathrm{FEV}_{1} \%$ pred, diurnal $\mathrm{PEF}$ variation and between-day PEF variation between subjects with a Borg score $>0$ and a score of zero are shown in table 2. Subjects with a Borg score $>0$ had a significantly lower FEV $1 \%$ pred $(-8.7 \%)$ and higher $\triangle \mathrm{FEV}_{1} \%$ pred $(+2.4 \%)$ than those with a score of zero (fig. 1). A score $>0$ was not asso-ciated with higher diurnal or between-day PEF variation.
Table 1. - Population characteristics according to Borg score

\begin{tabular}{|c|c|c|c|}
\hline \multirow[b]{2}{*}{ Males $n=88(42 \%)$} & \multicolumn{2}{|c|}{$\begin{array}{l}\text { Borg score }=0 \\
n=160(76 \%)\end{array}$} & $\begin{array}{c}\text { Borg score }>0 \\
n=50(24 \%)\end{array}$ \\
\hline & 65 & (41) & $23(46)$ \\
\hline Borg score ${ }^{+}$median (range) & & & $2.0(0.5-5.0)$ \\
\hline $\mathrm{FEV}_{1} \%$ pred $<80 \%$ & $13^{*}$ & (8) & $13(26)$ \\
\hline$\Delta \mathrm{FEV}_{1} \%$ pred $>9 \%$ & $12 *$ & (8) & $12(24)$ \\
\hline Diurnal PEF variation $>10 \%$ & 14 & (10) & $6(15)$ \\
\hline Age yrs $^{+}$ & 65 & (7) & 64 (7) \\
\hline Pack-years $^{+}$ & 11 & (19) & $13(15)$ \\
\hline Respiratory symptoms $(n=58)$ & 33 & $(21)^{*}$ & $25(50)$ \\
\hline Cardiac disease $(n=42)$ & 25 & $(16)^{*}$ & 17 (34) \\
\hline Overweight $(n=148)$ & 109 & (68) & $39(78)$ \\
\hline
\end{tabular}

Data presented as $\mathrm{n}(\%)$, except + mean (SD) and median (range) : tests performed on log 10-normalized data, values are geometric means (\%sD) [14]. FEV1: forced expiratory volume in one second; $\triangle \mathrm{FEV}$ 1: change in FEV1; PEF: peak expiratory flow. *: $\mathrm{p}<0.05$.

As shown in table 1 , subjects with a Borg score $>0$ had significantly more frequent respiratory symptoms and cardiac disease than those with a score of zero. An analysis was made of whether respiratory symptoms, cardiac disease and overweight were factors associated with FEV1\% pred, $\triangle F \mathrm{FV}_{1} \%$ pred and diurnal and between-day PEF variation in this elderly population. The results are shown in table 2.

Respiratory symptoms. Subjects with respiratory symptoms had a significantly lower FEV1 \% pred (-11.8\%) than those without respiratory symptoms. Respiratory symptoms were associated with increased diurnal and between-day PEF variation but not with a higher $\triangle \mathrm{FEV} 1$ $\%$ pred.

Cardiac disease. Subjects with cardiac disease had a significantly lower FEV1\% pred (-6.6\%) and a significantly higher between-day PEF variation than those with no cardiac disease. The presence of cardiac disease was not associated with $\triangle \mathrm{FEV} 1 \%$ pred.
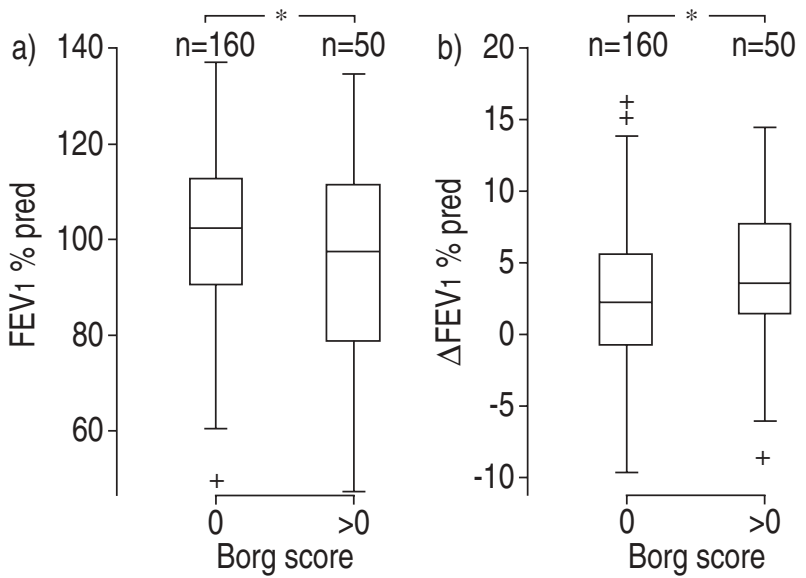

Fig. 1. - a) Forced expiratory volume in one second (FEV1) and b) change in $\left.\mathrm{FEV}_{1}(\triangle \mathrm{FEV})_{1}\right)$ as \% of predicted according to Borg scores of 0 and $>0 . *: p<0.05$ between Borg score of 0 and $>0$. Data were tested by linear regression with adjustment for age, sex, and pack-yrs. Box plots show median, 25 th, 75 th percentiles, with $1.5 \times$ the interquartile range. ${ }^{+}$: outliers. 
Table 2. - Estimated association between the presence of Borg score $>0$, respiratory symptoms, cardiac disease and weight and the forced expiratory volume in one second $\left(F E V_{1}\right) \%$ predicted, change in reversibility of $F E V_{1}\left(\Delta F E V_{1}\right) \%$ pred, diurnal peak expiratory flow (PEF) variation and between-day PEF variation

\begin{tabular}{|c|c|c|c|c|c|c|c|c|}
\hline & \multicolumn{2}{|c|}{ FEV1\% pred } & \multicolumn{2}{|c|}{$\triangle \mathrm{FEV}_{1} \%$ pred } & \multicolumn{2}{|c|}{$\begin{array}{l}\text { Diurnal PEF } \\
\text { variation }\end{array}$} & \multicolumn{2}{|c|}{$\begin{array}{c}\text { Between-day PEF } \\
\text { variation }\end{array}$} \\
\hline & B & SE & B & SE & $\mathrm{B}^{\dagger}$ & SE & $\mathrm{B}^{\dagger}$ & SE \\
\hline Borg score $>0(n=50)$ & $-8.7 *$ & (3.2) & $2.4 *$ & $(0.9)$ & 0.01 & $(0.06)$ & 0.09 & $(0.06)$ \\
\hline Respiratory symptoms $(n=58)$ & $-11.8 *$ & (3.0) & 0.1 & $(0.9)$ & $0.13^{*}$ & $(0.05)$ & $0.13 *$ & $(0.05)$ \\
\hline Cardiac disease $(n=42)$ & $-6.6^{*}$ & (3.5) & 0.2 & (1.0) & $0.12 \ddagger$ & $(0.06)$ & $0.15^{*}$ & $(0.07)$ \\
\hline Overweight $(\mathrm{n}=148)$ & $-9.3 *$ & (3.0) & 1.5 & $(0.8)$ & 0.06 & $(0.06)$ & $0.12 *$ & $(0.05)$ \\
\hline
\end{tabular}

Regression coefficients (B) represent the percentage differences in FEV1 ( $\triangle \mathrm{FEV}_{1} \%$ pred), diurnal PEF variation and between-day $\mathrm{PEF}$ variation in subjects with Borg score $>0$, respiratory symptoms, cardiac disease, or overweight compared to those without these characteristics. Linear regression performed for all independent variables separately, with adjustment for age, sex and pack-yrs. *: $\mathrm{p}<0.05 ;: \mathrm{p}<0.10 ;$ : estimates based on regressions performed on $\log 10$-normalized data.

Overweight. Subjects who were overweight had a significantly lower FEV1 \% pred (-9.3\%) and higher between-day PEF variation than subjects of normal weight. Overweight was not significantly associated with $\triangle \mathrm{FEV}_{1} \%$ pred or diurnal PEF variation.

Logistic regression was performed with $\mathrm{FEV}_{1} \%$ pred $<80 \%$ (low lung function), $\Delta \mathrm{FEV} 1 \%$ pred $>9 \%$ (reversibility) and diurnal PEF variation $>10 \%$ (high diurnal PEF variation) as dependent variables, and Borg score $>0$, respiratory symptoms, cardiac disease and overweight as independent variables. Borg score $>0$, respiratory symptoms, cardiac disease and overweight were all entered simultaneously into the model, to entangle their independent effects. The results are shown in table 3 . Subjects with a Borg score $>0$ had a significantly increased risk of low lung function $(\mathrm{OR}=3.4)$ and reversibility $(\mathrm{OR}=4.7)$ when respiratory symptoms, cardiac disease and overweight were taken into account. Subjects with respiratory symptoms as assessed by the questionnaire had an increased risk of low lung function level $(\mathrm{OR}=3.6)$ and high diurnal PEF variation $(\mathrm{OR}=7.7)$, which persisted after adjustment for Borg score $>0$, cardiac disease and overweight. Overweight by itself was shown to be a strong predictor of low lung function $(\mathrm{OR}=25.4)$. Cardiac disease, however, was no longer associated with increased risk for low lung function when Borg score $>0$, respiratory symptoms and overweight were taken into account.

There were no significant interactions between a Borg score $>0$ and respiratory symptoms, cardiac disease or overweight. This means that the associations described were no different for subjects with and without breathlessness. An analysis using a linear regression model confirmed the results of the logistic model.

The $\triangle \mathrm{FEV} 1 \%$ pred, diurnal PEF variation and betweenday PEF variation were all significantly and negatively associated with the FEV1 \% pred (Spearman's $\mathrm{r}=-0.28$, $\mathrm{r}=-0.37$ and $\mathrm{r}=-0.22$, respectively). The $\Delta \mathrm{FEV} 1 \%$ pred was not associated with diurnal PEF variation or betweenday PEF variation, either in subjects with a Borg score $>0$, respiratory symptoms, cardiac disease or overweight, or in the total population.

In the presented analyses subjects with a Borg score $>0$ were labelled as having "breathlessness". When the analyses were repeated using another cut-off point on the Borg scale to define breathlessness (e.g. Borg score $\breve{S} 1, n=40$, or Borg score $\check{S} 2, n=27$ ) the results remained essentially unchanged.

\section{Discussion}

Breathlessness as measured with the Borg score was present in $24 \%$ of the elderly population in this study. Subjects with breathlessness had lower levels of lung function and were more likely to have reversibility of airway obstruction. This relation was present whether or not subjects had respiratory symptoms, cardiac disease or were overweight. Thus, if an elderly individual perceives breathlessness at rest this should always alert physicians to investigate for low lung function.

Worse levels of bronchoconstriction are related to perception of breathlessness [15]. Some studies show a decrease in the perception of bronchoconstriction at older ages. ConNolly et al. [16] showed that young asthma- tics were better perceivers of the same degree of bronchoconstriction than their elderly counterparts. The same agerelated difference in perception was found in non-asthmatic, healthy individuals [4]. Thus, in general, the number of elderly subjects that actually perceives bronchoconstriction is lower than the number that could be expected on the basis of the actual level of bronchoconstriction. This would mean that a part of the present elderly population had airway obstruction without a positive Borg score, reflecting reduced perception of breathlessness. Indeed, 13 out of the 26 elderly subjects with objective airway obstruction (FEV1 \% pred $<80 \%$ before bronchodilation) did not perceive breathlessness at the moment of investigation.

Although breathlessness is often considered as a single sensation, it may encompass multiple sensations that are not well explained by a single physiological mechanism [17]. One of the most frequently reported physiological causes of perception of breathlessness is cardiac disease [5]. In the current study, performed in a relatively healthy population of elderly subjects, $20 \%$ had cardiac disease; in these subjects the perception of breathlessness was frequently present $(40 \%)$. Subjects with cardiac disease had a lower FEV $1 \%$ pred and a higher diurnal and between-day PEF variation. However, the presence of cardiac disease was not an independent risk factor for low lung function or high diurnal PEF variation. Indeed, further analyses showed that cardiac disease was associated with low lung function and high diurnal PEF variation merely due to the presence of respiratory symptoms in $50 \%$ of those subjects with cardiac disease. Thus, the fact that these subjects had respiratory symptoms, and not the fact that they had cardiac disease, may explain the associ- 
Table 3. - Estimated independent effects of Borg score $>0$, respiratory symptoms, cardiac disease and overweight on the presence of low lung function, reversibility and high diurnal peak expiratory flow (PEF) variation

\begin{tabular}{lcccccc}
\hline & \multicolumn{2}{c}{ Low lung function } & \multicolumn{2}{c}{ Reversibility } & \multicolumn{2}{c}{ High diurnal PEF variation } \\
& OR & $(95 \% \mathrm{CI})$ & OR & $(95 \% \mathrm{CI})$ & OR & $(95 \% \mathrm{CI})$ \\
\hline Borg score $>0(\mathrm{n}=50)$ & $3.4^{*}$ & $(1.3-9.2)$ & $4.7^{*}$ & $(1.7-12.9)$ & 0.8 & $(0.2-2.6)$ \\
Respiratory symptoms $(\mathrm{n}=58)$ & $3.6^{*}$ & $(1.4-9.5)$ & 0.9 & $(0.3-2.6)$ & $7.7^{*}$ & $(2.3-25.5)$ \\
Cardiac disease $(\mathrm{n}=42)$ & 0.9 & $(0.3-2.7)$ & 0.9 & $(0.3-3.0)$ & 1.1 & $(0.3-3.9)$ \\
Overweight $(\mathrm{n}=148)$ & $25.4^{*}$ & $(2.3-277.0)$ & 1.4 & $(0.4-4.7)$ & 2.1 & $(0.5-8.0)$ \\
\hline
\end{tabular}

Logistic regression, adjusted for age, sex, pack-years and each other. Low lung function: forced expiratory volume in one second (FEV1) \% pred <80\%; reversibility: change in FEV1 \% pred $>9 \%$; high diurnal PEF variation: diurnal PEF variation $>10 \%$. Logistic regression performed with low lung function, reversibility and high diurnal PEF variation as dependent variables and Borg score $>0$, respiratory symptoms, cardiac disease and overweight as independent variables, with adjustment for each other and age, sex and packyears. Odds ratios $(\mathrm{OR})$ represent the increased risk for the presence of low lung function, reversibility and high diurnal PEF variation in subjects with Borg score $>0$, respiratory symptoms, cardiac disease and overweight compared to those without these characteristics. CI: confidence interval. *: $\mathrm{p}<0.05$.

ations found between cardiac disease and lower FEV1\% pred and higher diurnal PEF variation.

Previous population studies have shown that respiratory symptoms are present in approximately $40-60 \%$ of the elderly $[13,18]$, whereas $28 \%$ of the present elderly subjects had respiratory symptoms. This somewhat low prevalence of respiratory symptoms is probably due to the method of population sampling. This study probably included the healthier part of the elderly population, i.e. those willing and able to perform physical exercise. Notwithstanding this, the frequency of morbidity was substantial. Breathlessness was present frequently in this group and significant associations were found between breathlessness and clinically relevant reduced levels of lung function and increased bronchodilator response.

The lower frequency of respiratory symptoms may also be a consequence of not including breathlessness on exertion as one of the respiratory symptoms. Breathlessness on exertion was excluded because this symptom is associated not only with the presence of respiratory disease, but also with cardiac disease and combinations of both diseases [19]. Because the aim was to investigate whether the relation between lung function impairment and perception of breathlessness was modified by cardiac disease, symptoms caused by both cardiac and respiratory disease were excluded.

Irrespective of whether subjects had respiratory symptoms, those with breathlessness as assessed with the Borg score were much more likely to have a low lung function level and reversibility than those without breathlessness. This difference could not be explained by age, smoking habits or sex. This stresses the importance of breathlessness as an indicator of lung function impairment in subjects who are considered to have good respiratory health.

The Borg score reflects breathlessness "at-the-moment". Because the Borg score and reversibility are strongly related, reversibility is also assumed to be a momentary reflection of the airway lability of an individual. This interpretation of reversibility, as a variable expression of airway lability, is in accordance with previous suggestions [20], as well as with the results of an early study by ANTHonisen et al. [21]. They measured reversibility every 3 months, for $3 \mathrm{yrs}$, in a large group of COPD patients and showed that reversibility varied greatly with time, both between and within patients. In contrast to patients with respiratory disease, reversibility may vary less over time in healthy individuals, since the present study shows that their $\triangle \mathrm{FEV} 1 \%$ pred is, on average, small and variability in bronchodilation tends to be small in those with low initial $\triangle \mathrm{FEV}_{1} \%$ pred [21].

Contrary to the interpretation of reversibility of airway obstruction as a time-changing expression of airway lability, PEF variability seems to express an individual's average state of airway lability over a longer period. This suggestion arises from the relationship that was found between the presence of respiratory symptoms in the last 12 months and PEF variability. The fact that no association was found between respiratory symptoms and reversibility corroborates this hypothesis. Overall, this study showed that PEF variability and $\triangle \mathrm{FEV}_{1} \%$ pred are not to any extent associated with each other. This suggests that both variables reflect distinct underlying phenomena.

The aim of this study was to assess the prevalence of breathlessness in the elderly and whether breathlessness was independently associated with low lung function, reversibility of airway obstruction and variability in peak expiratory flow. The results showed that breathlessness was related to low lung function and reversibility. Neither respiratory symptoms, cardiac disease nor overweight were underlying factors that could explain this relation. It was concluded that breathlessness as assessed with a Borg score is frequently present in relatively healthy, elderly subjects. In these subjects, it is a predictor for the presence of a low level of lung function and reversibility of airway obstruction, but it does not predict the presence of variability in peak expiratory flow. In both clinical and research settings, assessment of breathlessness using the Borg scale seems an important clinical measurement, because it provides a significant indicator for lung function impairment in relatively healthy, elderly subjects.

\footnotetext{
Acknowledgements: The data were collected in the study "Fitness, medical consumption and life-style in subjects aged Š55 yrs in the county of Drenthe, The Netherlands", performed by the Working Group Human Movements Sciences, University of Groningen, The Netherlands. Glaxo Pharmaceuticals provided peak flow meters and bronchodilator medication.
}

\section{References}

1. Burdon JGW, Juniper EF, Killian KJ, Hargreave FE, Campbell EMJ. The perception of breathlessness in asthma. Am Rev Respir Dis 1982; 126: 825-828. 
2. Boulet LP, Milot J, Turcotte H. Relationship between changes in diurnal variation of expiratory flows, lung volumes and respiratory symptoms after acute asthma. Respir Med 1991; 85: 487-493.

3. Noseda A, Schmerber J, Prigogine T, Yernault JC. Perceived effect on shortness of breath of an acute inhalation of saline or terbutaline: variability and sensitivity of a visual analogue scale in patients with asthma and COPD. Eur Respir J 1992; 5: 1043-1053.

4. Brand PLP, Rijcken B, Schouten JP, Koëter GH, Weiss ST, Postma DS. Perception of airway obstruction in a random population sample. Am Rev Respir Dis 1992; 146: 396-401.

5. Vestbo J. Predictors of mortality, COPD morbidity, and respiratory cancer. Danish Med J 1993; 40: 1-16.

6. Sorlie PD, Kannel WB, O'Connor G. Mortality associated with respiratory function and symptoms in advanced age. Am Rev Respir Dis 1989; 140: 379-384.

7. Borg G. Perceived exertion as an indicator of somatic stress. Scan J Rehab Med 1970; 23: 92-98.

8. Burney PGJ, Luczynska C, Chinn S, Jarvis D. The European Respiratory Health Survey. Eur Respir J 1994; 7: 954-960.

9. Tomkins A. Nutrition in clinical medicine. In: Souhami RL, Moxham J, eds. Textbook of Medicine. Edinburgh, Churchill Livingstone, 1990; pp. 117-138.

10. Quanjer PH, Tammeling GJ, Cotes JE. Lung volumes and forced ventilatory flows: report working party standarization of lung function tests. European Community for Coal and Steel. Eur Respir J 1993; 6: 5-40.

11. Dales RE, Spitzer WO, Tousignant P, Schechter MT, Suissa S. Clinical interpretation of airway response to a bronchodilator: epidemiological considerations. Am Rev
Respir Dis 1988; 138: 317-320.

12. Quackenboss JJ, Lebowitz MD, Krzyzanowski M. The normal range of diurnal changes in peak expiratory flow rates. Am Rev Respir Dis 1991; 143: 323-330.

13. Boezen HM, Schouten JP, Postma DS, Rijcken B. Relation between respiratory symptoms, pulmonary function and peak flow variability in adults. Thorax 1995; 50: 121-126.

14. Snedecor GW, Cochran WG. Statistical Methods. Ames, Iowa State University Press, 1967; pp. 299-338.

15. Turcotte H, Boulet LP. Perception of breathlessness during early and late asthmatic responses. Am Rev Respir Dis 1993; 148: 514-518.

16. Connolly MJ, Crowley JJ, Charan NB, Nielson CP, Vestal RE. Reduced subjective awareness of bronchoconstriction provoked by methacholine in elderly asthmatic and normal subjects as measured on a simple awareness scale. Thorax 1992; 47: 410-413.

17. Simon PM, Schwartzstein RM, Weiss JW, et al. Distinguishable sensations of breathlessness induced in volunteers. Am Rev Respir Dis 1989; 140: 1021-1027.

18. Dow L, Coggon D, Osmond C, Holgate ST. A population survey of respiratory symptoms in the elderly. Eur Respir $J$ 1991; 4: 267-272.

19. Eriksson H, Svärdsudd K, Larsson B, et al. Dyspnoea in a cross-sectional and a longitudinal study of middle-aged men: the study of men born in 1913 and 1923. Eur Heart $J$ 1987; 8: 1015-1023.

20. Enright PL, Lebowitz MD, Cockcroft DW. Physiologic measures: pulmonary function tests: asthma outcome. Am J Respir Crit Care Med 1994; 149: S9-S20.

21. Anthonisen NR, Wright EC, IPPB Trial Group. Bronchodilator response in chronic obstructive pulmonary disease. Am Rev Respir Dis 1986; 133: 814-819. 